\title{
Análisis de la violencia cibernética en las preparatorias pertenecientes a la Universidad Autónoma de Nuevo León del municipio de Monterrey.
}

\author{
Luz Alejandra Escalera Silva \\ luz.escaleraslv@uanl.edu.mx \\ Facultad de Trabajo Social y Desarrollo Humano, UANL.
}

\section{RESUMEN}

El fenómeno conocido como ciberbullying ha llamado la atención de los investigadores de las ciencias sociales debido al impacto en la conducta de los estudiantes de los centros educativos. El presente estudio de diseño mixto intenta dar cuenta de la forma en la que este fenómeno se presenta en las preparatorias de la Universidad Autónoma de Nuevo León, pertenecientes al Municipio de Monterrey. Entre los resultados más importantes destaca que las experiencias de ciberbullying se encuentran mediadas a partir de la interacción entre los factores personales, interpersonales y las motivaciones externas de los sujetos, constituyendo estos elementos los determinantes fundamentales del fenómeno del ciberbullying.

Palabras clave: Ciberbullying; Bullying; Violencia escolar; Redes sociales. 


\title{
Analysis of cyber violence in high schools belonging to the Universidad Autónoma de Nuevo León of Monterrey.
}

\begin{abstract}
:
The phenomenon known as cyberbullying has attracted the attention of social science researchers because of its impact on the behavior of students in educational centers. The present study of mixed design tries to give an account of the way in which this phenomenon is presented in the high schools of the Universidad Autonoma de Nuevo Leon, belonging to the Municipality of Monterrey. Among the most important results, it stands out that cyberbullying experiences are mediated from the interaction between personal and interpersonal factors and the external motivations of the subjects, constituting these elements the fundamental determinants of the cyberbullying phenomenon.
\end{abstract}

Keywords: Cyberbullying; Bullying; School violence; Social networks

Artículo recibido: 26. julio. 2020 Aceptado para publicación: 09. setiembre. 2020 Correspondencia: luz.escaleraslv@ uanl.edu.mx aleluz.escalera@gmail.com Conflictos de Interés: Ninguna que declarar 


\section{INTRODUCCIÓN}

Los procesos de cambio social en el sistema educativo se han acelerado en los últimos años. Entre ellos el bullying ha recibido una atención especial, debido a su impacto en la conducta de los estudiantes en diferentes niveles de la educación. Esta situación ha llamado la atención, tanto a las autoridades académicas como a investigadores de las ciencias sociales (Berkowitz, 1996; Escalera, et. al., 2019).

Este fenómeno social se ha presentado en diferentes manifestaciones (Redorta, 2004); por una parte, el bullying físico, que incluye todo tipo de acción corporal como empujones, golpes, daños a pertenencias, entre otros (Estevez, 2005). Esta es la forma más común de bullying, a su vez, es la forma que con mayor facilidad se identifica, pues frecuentemente deja huellas corporales. De acuerdo con autores como Cobo y Tello (2008), este tipo de acoso es el más peligroso debido a un escalamiento acompañado por una intención dirigida a lastimar con un incremento progresivo. Por otra parte, el bullying Gesticular, que consiste en agresiones que resultan más difíciles de detectar, porque pueden consistir en una mirada, una señal desagradable, un gesto, etc. Se trata de formas de agresión, amenaza o exclusión que por lo común se llevan a cabo a espaldas de cualquier persona que pueda advertir la situación y, en consecuencia, ayudan a quien expresa estos gestos y señas a permanecer en el anonimato. Además, es posible mencionar el bullying verbal, que consiste en acciones no corporales -pero igualmente dañinas- como poner apodos, insultar, difundir rumores, expresiones raciales o sexistas, con el objetivo de menospreciar a la víctima. Este tipo de bullying es el que se presenta de manera más frecuente (Harries, 2003). En relación a este último tipo de bullying, relacionado íntimamente con la difusión de rumores, es necesario mencionar que como fenómeno social ha recibido el impacto del desarrollo de la tecnología de la información y comunicación. Durante los últimos años con la aparición del internet, y las redes sociales cibernéticas, esta práctica se ha hecho común entre los jóvenes, sobre todo aquellos que cursan la educación media superior.

En este contexto, esta investigación busca conocer el impacto emocional, generado por el bullying cibernético en los estudiantes de este nivel educativo y al mismo tiempo, contribuir a su disminución a través de los métodos alternos de solución de conflictos.

La pertinencia de esta investigación radica en que actualmente la violencia escolar ya no se limita únicamente al ámbito de los espacios físicos de las escuelas del nivel medio superior, el acoso de alumnos contra alumnos, continua a través de las nuevas tecnologías de la información y la comunicación. En la práctica lo que se conoce como "ciberbullying", es un fenómeno que está cada vez más presente en nuestra realidad, sin ningún tipo de prevención o gestión del conflicto, los bully o ciberbully, difunden rumores a través de Internet y sus diferentes redes sociales, en completa impunidad.

Dicha situación afecta el impacto emocional de los estudiantes del nivel medio superior, ya que por medio de las nuevas tecnologías el bully cibernético, puede llegar a su víctima 
desde cualquier lugar y en cualquier momento, sin necesidad de estar frente a frente, ya que el "ciberespacio" cada día tiene mayor peso en la socialización de los estudiantes de bachillerato. Por esto, el cyberbullying pudiera llegar a ser más traumático que una situación de abuso en las aulas.

Además, igual a lo que pasa con el bullying tradicional, el estudiante está inmerso en tanto estrés, que su rendimiento académico baja, en medida que el ciberbully esté presente en su mundo cibernético. Asimismo, el conflicto que se crea también afecta a las familias de los estudiantes, al sentirse impotentes ante la situación, y no saber cómo apoyarlos. Se puede agregar, que la violencia psicológica generada, ocasiona un daño mayor en la víctima debido a que este tipo de conducta (a diferencia del bullying tradicional), no estriba en la cantidad de veces en que es atacada, sino en que la forma de agresión es expuesta ante los demás, con la intención de ridiculizarla y desprestigiarla. Esta situación propicia un grave daño moral, que a su vez, en ocasiones es generador de violencia física. De cierta manera se trata de un fenómeno que está creciendo exponencialmente, sin embargo y a pesar de su fuerte incidencia, no existen programas educativos de mediación para encarar este problema. Lo anterior nos llevó a preguntarnos ¿cómo se presenta el ciberbullying en las preparatorias del Municipio de Monterrey y cuál es su impacto entre los adolescentes que lo han experimentado? Para a partir de esto, aspirar al desarrollo de mecanismos de intervención para la disminución del mismo.

\section{MATERIALES Y MÉTODOS}

En el siguiente apartado se propone la estructura metodológica a seguir para el presente estudio sobre el ciberbullying.

Abordar por un lado la incidencia y experiencia de los jóvenes que cursan el nivel medio superior en las preparatorias pertenecientes a la UANL, del municipio de Monterrey en el fenómeno y por otro lado que el estudio de estos casos existentes nos brinde una visión clara del impacto del ciberbullying de tal manera que permita desarrollar mecanismos de intervención para la disminución del mismo.

Este estudio de diseño mixto está constituido por dos etapas, donde los hallazgos de la metodología utilizada en la primera etapa del estudio, en este caso la cualitativa, contribuye en el desarrollo o a informar la segunda etapa cuantitativa. El supuesto en el cual se basa el uso de este diseño es que la exploración es un requisito necesario para la segunda fase del estudio. El panorama de la estrategia puede quedar resumida en la siguiente tabla (véase tabla 1). 
Tabla 1: Estrategia Metodológica en el estudio del ciberbullying.

\begin{tabular}{|c|c|}
\hline \multicolumn{2}{|l|}{ Estrategia Metodológica } \\
\hline Tipo de estudio: mixto. & $\begin{array}{l}\text { Diseño del estudio: secuencial, no experimental y de } \\
\text { tipo explicativo }\end{array}$ \\
\hline \multicolumn{2}{|l|}{ Características del diseño. } \\
\hline Cualitativo. & Cuantitativo. \\
\hline $\begin{array}{l}\text { Marco interpretativo: fenomenología, } \\
\text { codificación e interpretación. } \\
\text { Recopilación de datos: entrevista a } \\
\text { profundidad. }\end{array}$ & $\begin{array}{l}\text { Recopilación de datos: derivado de la muestra } \\
\text { cualitativa: caracterización sociodemográfica de los } \\
\text { sujetos de estudio, derivado de los datos arrojados } \\
\text { por las entrevistas semi estructuradas. }\end{array}$ \\
\hline \multicolumn{2}{|l|}{ Muestra: intencional por criterios: } \\
\hline Análisis de datos: etnograph & \\
\hline Escenario de trabajo: preparatorias $U$ & as en el municipio de Monterrey. \\
\hline
\end{tabular}

(Elaboración propia)

Esta investigación se centró en la exploración de los significados subjetivos que los estudiantes inmersos en el ciberbullying tuvieron como resultado de las experiencias del fenómeno. Es por esta razón, que la interpretación de estas experiencias necesitó de un abordaje preponderantemente cualitativo. A través de una entrevista semiestructurada aplicada a una muestra intencional por criterios, para nuestro estudio elegimos adolescentes que cursan el nivel medio superior que han sido víctimas o generadores de violencia cibernética, para a través de sus opiniones tener un mejor contexto de la situación en que vivieron el fenómeno. El contexto de la investigación abarcó las ocho preparatorias pertenecientes a la Universidad Autónoma de Nuevo León en el municipio de Monterrey. A continuación, en la siguiente tabla explicaremos las categorías en las que se centró nuestro estudio.

Tabla 2: Categorías que fueron estudiadas entorno al fenómeno ciberbullying

\begin{tabular}{|l|l|}
\hline \begin{tabular}{|l|} 
Categorias que fueron estudiadas entorno al fenómeno ciberbullying \\
\hline Categorías
\end{tabular} & \multicolumn{1}{c|}{ Descripción } \\
\hline Las motivaciones del agresor. & $\begin{array}{l}\text { Entendiéndose como envidia, celos, violencia, } \\
\text { venganza. }\end{array}$ \\
\hline
\end{tabular}




\begin{tabular}{|ll|}
\hline Factores personales. & $\begin{array}{l}\text { Información sobre sexo, rendimiento académico, } \\
\text { autoestima positiva y negativa. }\end{array}$ \\
\hline Factores interpersonales y de contexto. & $\begin{array}{l}\text { Conductas violentas, ajuste social con los iguales, } \\
\text { contexto social, económico, demográfico }{ }^{1} .\end{array}$ \\
\hline Las estrategias para intervenir. & $\begin{array}{l}\text { Información respecto a los posibles mecanismos } \\
\text { para intervenir en el ciberbullying. }\end{array}$ \\
\hline Las consecuencias. & $\begin{array}{l}\text { Información respecto a las consecuencias sufridas a } \\
\text { causa de la inmersión en el fenómeno estudiado. }\end{array}$ \\
\hline
\end{tabular}

(Elaboración propia)

La interpretación de la información se llevó a cabo empleando el marco interpretativo de la fenomenología. Dicha perspectiva es un estilo de investigación cualitativa que define el significado de las experiencias de vida de un individuo, es una aproximación a la comprensión de la perspectiva de una persona. Por lo tanto la fenomenología brindó los elementos de análisis de las experiencias del estudiante entrevistado, es decir, a través del análisis e interpretación desde el marco fenomenológico se conoció el universo de los sujetos que participaron en el desarrollo del fenómeno ciberbullying.

Con respecto al enfoque cuantitativo, nos resultó relevante, exponer una caracterización del perfil sociodemográfico de los estudiantes entrevistados, ya que estas características son un reflejo de la situación social de cada individuo. La aproximación cuantitativa consistió en definir el entorno social y demográfico de los jóvenes entrevistados a partir del sito de residencia. Para lograr este objetivo se utilizó el Inventario Nacional de Viviendas del INEGI, que consiste en un sistema de información geográfica (SIG) que a partir de la utilización de los datos obtenidos por el Censo Nacional de Población y Vivienda realizado en 2010, en conjunto con otras bases de datos como la correspondiente a la medición de pobreza del CONEVAL, permite obtener los principales indicadores sociales, económicos y demográficos de zonas geográficas particulares. La ventaja de este sistema es que opera con un nivel de desagregación que posibilita obtener información por entidad, municipio, localidad, AGEB y manzana urbana. Esto permite que los indicadores demográficos y socioeconómicos sean obtenidos con el máximo nivel de desagregación posible, permitiendo con ello una caracterización socio demográfica con un mayor nivel de profundidad considerando que el sitio de residencia a estos niveles de desagregación (manzana y AGEB) dan mayor cuenta de la posición social de los hogares de los jóvenes entrevistados. Posteriormente, se realizó una lista de las colonias en donde residen los participantes de la investigación, que habían sido previamente identificadas a partir de las entrevistas realizadas. Una vez identificados estos sitios de residencia, se procedió a

\footnotetext{
${ }^{1}$ Entendiendo que esta categoría fue analizada por medio de un enfoque cuantitativo, sin embargo, la obtención de los datos necesarios para su estudio fueron derivados de la entrevista semi estructurada.
} 
identificarlos mediante el SIG señalado, que además de la obtención de algunos indicadores nos permitió conocer el código de AGEB correspondiente a cada colonia. La ubicación de este código sirvió para localizar los indicadores restantes directamente de la base de datos del Censo Nacional de Población y Vivienda 2010. Una vez obtenida la información, se realizaron tablas de frecuencia para facilitar el análisis.

Finalmente, la presentación de la información se realizó en cinco apartados, que se desarrollarán en el de análisis de los datos obtenidos.

\section{RESULTADOS.}

\section{Factores personales, motivaciones internas.}

De acuerdo a la literatura citada, los factores personales definen cuestiones como el sexo, la edad, el rendimiento académico, la autoestima de un individuo que juega alguno de los roles implicados en el ciberbullying.

$\underline{\operatorname{SexO}}$

Con respecto al sexo, en este estudio cualitativo se entrevistaron a diez sujetos de estudio, cinco que jugaron el rol de víctimas y cinco que jugaron el rol de victimarios, resultando que:

Tabla 3: Personas entrevistadas

\begin{tabular}{|l|l|}
\hline \multicolumn{2}{|c|}{ Personas entrevistadas según el sexo y el rol en la participación de ciberbullying } \\
\hline Víctimas & $\begin{array}{l}\text { Se entrevistaron a cinco sujetos jugando el papel de víctimas, de los cuales } 3 \\
\text { fueron mujeres y } 3 \text { fueron hombres. }\end{array}$ \\
\hline Agresores & $\begin{array}{l}\text { Se entrevistaron a cinco sujetos jugando el papel de agresores, de los cuales } 3 \\
\text { fueron mujeres y } 2 \text { fueron hombres. }\end{array}$ \\
\hline $\begin{array}{l}\text { Espectadores } \\
\text { participantes en la } \\
\text { agresión }\end{array}$ & $\begin{array}{l}\text { Se entrevistaron } 10 \text { sujetos de estudio, } 5 \text { jugando el papel de víctimas, } 5 \\
\text { jugando el papel de agresores, de los cuales } 10 \text { sujetos señalaron haber } \\
\text { participado alguna vez en la agresión de manera indirecta. }\end{array}$ \\
\hline
\end{tabular}

(Elaboración propia)

Los estudios de Mateo et. al (2010) y Ortega (2008) indicaron que las chicas muestran una mayor predisposición a participar como víctimas y los chicos como agresores. Sin embargo, nosotros coincidimos con Álvarez García et al, (2011) y Beran y Li, (2007), cuyas investigaciones no han advertido diferencias en función del sexo. Sin embargo, sí encontramos una diferencia alarmante, misma que consiste en que la intencionalidad del acto ya sea por agresores hombres o mujeres, va directamente al desprestigio social de la 
víctima de sexo femenino, situando a la usuaria mujer más vulnerable frente al usuario hombre.

Otro dato que nos resulta alarmante y que abordaremos más adelante ${ }^{2}$ es el papel del espectador participante, ya que los 10 sujetos que se entrevistaron manifiestan alguna vez haber perpetuado violencia indirecta sobre otro.

\section{$\underline{\text { Rendimiento académico. }}$}

En tanto al rendimiento escolar, autores como Olewus (2012), afirman que los agresores del bullying tradicional tienden a tener un rendimiento escolar bajo. A este respecto, se suman Beran \& Li, (2008) y Schneider et al., (2012), que en sus estudios encontraron que los agresores victimizados ( (Aviles, García-López, \& Caballo, 2011), tienen malos promedios escolares respecto a los alumnos no implicados en ciberbullying. En cambio, García et al. (2010) sostiene que "tanto "ciberagresores" como "cibervíctimas" autoperciben su rendimiento como medio-bajo. ”

En cuanto al rendimiento escolar, encontramos que los promedios académicos generales de los agresores están en un rango entre 9.5 y 8.7.

"bien, me va bien, la escuela es fácil, dejé materias por flojo alguna vez, pero nunca he tenido gran problema, ahorita ya me va mejor, no sé, el semestre pasado pos como 90, 92, no sé, la escuela es fácil, las materias son fáciles." (G., 18 años).

"Soy bueno, siempre he sido buen estudiante, estoy en los promedios más altos de mi generación." (P., 17 años).

En tanto que el rendimiento escolar de las víctimas fue de promedios generales de entre 9.0 a 6.9 .

"No tengo promedio tan bajo pero no es alto, en realidad no es como que me esfuerzo mucho en la escuela, no me gusta venir, no me gusta participar en clase, es aburrido, las clases son aburridas, los maestros se sientan y te dan el libro de competencias y ahí está, uno solo viene a hacer sus actividades esas, ellos las revisan y quieren que participemos en todo, no me gusta la escuela, no sé mi promedio porque apenas estoy en primer semestre pero a lo mejor dejo entre tres o cuatro materias, matemáticas es seguro y pema." (A., 16 años).

“ammm pues bien bien jaja no. Sí studio pero a veces no es suficiente, y con todo esto que pasó (lo del bullying por face) me daba vergüenza venir a la escuela, que me vieran, no quería ver a nadie, empecé a faltar a clases, no culpo de todo a esto

${ }^{2}$ Se abordará en el apartado de factores interpersonales y de contexto. 
que pasó pero yo digo que sí me afectó al grado de que no quisiera pararme por la escuela y dejé materias por faltas y por no entregar trabajos, todo eso." (V., 17)

Podemos señalar que a diferencia de otros autores, los sujetos de estudio entrevistados que juegan el rol de agresores se perciben a sí mismos como buenos estudiantes con promedios escolares arriba de la media, frente a los promedios bajos de las víctimas entrevistadas.

Algo nos resulta importante destacar es la negatividad con la que el alumno que juega el papel de víctima de ciberbullying percibe la experiencia escolar.

\section{$\underline{\text { Autoestima }}$}

En relación a los factores personales si analizamos al agresor, en la mayoría de los casos se trata de una persona con problemas de baja autoestima (Olewus D. ,2005) sin embargo, otros estudios como el de Trautmann (2008) han tenido como resultados que los agresores se perciben superiores a los demás, ya sea porque tienen compañeros que los apoyan o porque es su manera de responder a las agresiones.

En la presente investigación encontramos que los agresores que fueron entrevistados no se perciben a sí mismos como personas con problemas de estima baja, por el contrario, consideran que son personas listas y con buena relación con los demás. A diferencia de las víctimas entrevistadas que manifiestan que con el acto de agresión cibernética la seguridad que sentían disminuyó al grado de sentirse inferiores frente a otras personas.

"Algunas personas son muy inseguras y es muy fácil hacerlas sentir mal. Deberían trabajar en su autoestima. Dan lástima” (P., 17 años).

"Mal, me sentí muy humillada, muy triste, todavía me siento así, no quería salir de mi casa, no quería ir a la escuela, todos me iban a mirar pensando que yo era esto y el otro, la prepa es muy difícil, lo que haces o dicen se te queda y me estaban afectando mi reputación con chismes y cosas feas, pensé que me iba a morir. Mi autoestima bajó mucho." (K., 17 años).

Otro punto que nos llama la atención es que los agresores entrevistados, señalaron que sus ataques eran con el propósito de hacer sentir "menos" a sus víctimas.

"la verdad ni pensé en eso de cómo se sentían, o sea sí, pero no, pues esperaba que se enojara, que se sintiera mal, por ridícula, es que fueron a muchas personas, pero sí, siempre quería que se enojaran o que se sintieran, es que no sé, yo lo hacía para hacer reír también, en broma." (R., 18 años). 
"Fue directa, yo sentía que ella se lo merecía por roba novios, ella sabía que éramos mis amigas y yo, nunca me reclamó, ni nada, iba a llorarle a mi ex y le decía que yo era mala, tenía motivos para ser mala. Quería que se sintiera mal, que lo dejara." (J., 17 años).

Podemos inferir que los ataques directos hacia las víctimas seleccionadas fueron con el objetivo claro de que el abuso cibernético impactara directamente en su autoestima. Además, algo que resulta relevante es que parte de la motivación del ataque no fue solo que impactara en la autoestima de la víctima sino en satisfacer una percepción que el agresor construyó de justicia.

\section{Motivaciones internas}

Son muchos los autores que afirman que el ciberbullying está motivado por factores internos, propios de una situación determinada, estos van encaminadas a producir un daño a la víctima y son producto de diferentes motivos, características y contextos sociales que condicionarían a los agresores a perpetrar sus actos. Así, encontramos motivaciones internas como la venganza, el aburrimiento o los celos (Hinduja \& Patchin, 2013; Konig, Maekawa, \& Schiebel, 2010; Garaigordobil M. , 2013; Calmaestra J. , 2011).

Así como estos autores, en nuestro estudio encontramos que los estudiantes entrevistados en el rol de victimarios tenían un motivo claro para efectuar el acto.

Las motivaciones internas que encontramos en los casos de los entrevistados que jugaron el papel de agresores fueron diversas, van desde los celos, el aburrimiento hasta la venganza. Dos informantes manifestaron que motivado por celos hacia la nueva pareja de su ex pareja, tres que fueron movidos por el deseo de venganza hacía personas que en alguna ocasión los hizo sentir vulnerables o violentados, uno de los sujetos señaló que el origen de la agresión fue a causa de aburrimiento.

"Me hizo sentir bien porque le caló, lo merecía y no estaba diciendo mentiras, todo eso ella era, todo lo que me hizo, lo que pasé, no valía, ella no valía." (G., 18 años).

Los entrevistados, tanto víctimas como agresores mencionaron que han sido generadores indirectos de violencia compartiendo imágenes, estados o diferentes informaciones que otros sujetos han subido en la red por diversión.

"No, bueno sí, pero nunca compartí con el afán de molestar como me lo hicieron a mí, mmm... solo imágenes, bueno, si viéndolo ahorita si pude compartir imágenes parecidas algo parecido a lo que a mí me hicieron." (M., 17 años). 
"La verdad si compartí, me burlé. Ahora me siento mal de haberlo hecho, no sabes si lo que dicen es cierto y compartes porque te crees gracioso el contenido pero a alguien más le estas afectando." (K., 17 años).

"Cómo comparto imágenes, fotos, de otras personas que a veces ni conozco pero es chistoso, la información que se comparte es publica, es problema del que la sube por mongol" (R., 17 años).

\section{Factores interpersonales y de contexto del agresor:}

\section{Ajuste social}

Los estudiantes entrevistados para esta investigación, tanto víctimas como agresores, admitieron haber participado en alguna ocasión con la violencia cibernética de manera indirecta, es decir, no como terceros neutrales o sujetos jugando el papel de espectadores, sino siendo generadores de la violencia al compartir las publicaciones de otros usuarios vulnerando a alguna persona en sus redes sociales. En este sentido, resulta relevante resaltar que a diferencia del bullying tradicional, en el que el papel del tercero espectador no genera directamente un daño, en el ciberbullying, el tercero deja de ser un testigo del acto para convertirse en un generador indirecto de la violencia cibernética, de esta manera, nos parece importante señalar que el entorno social cibernético es determinante, propiciando que el generador de violencia indirecto se una al fenómeno en su ajuste social.

“¿Cómo participado indirectamente? O sea si compartí cosas? sí. Me da pena decirlo pero sí. No es algo que piense volver a hacer pero sí lo he hecho y nunca me puse en el lugar de la persona, compartí porque era gracioso y ahora veo que no tiene nada de gracioso. Lastimas mucho. Llega a más gente, te vuelves parte del círculo." (I., 17 años).

\section{Contexto social del agresor}

Etimológicamente hablando, no nos resulta correcto generalizar las características de residencia de los estudiantes, sin embargo, nos pareció relevante atendiendo al contexto social del estudiante agresor determinar las características sociodemográficas de sus residencias, mismas que consideramos son un reflejo importante de la posición del individuo y de su situación socioeconómica.

Entre los agresores que entrevistamos, nos encontramos con que cuatro de ellos viven en el municipio de Guadalupe y uno en el municipio de Monterrey. 
Tabla 4: Contexto del Agresor

\begin{tabular}{lcll}
\hline Agresor & Edad & Municipio & Colonia \\
\hline Agresor 1 & 17 & Guadalupe & Valle del Contry \\
Agresor 2 & 18 & Guadalupe & Nueva Linda vista \\
Agresor 3 & 17 & Guadalupe & La primavera \\
Agresor 4 & 17 & Guadalupe & Bosques del Contry \\
Agresor 5 & 18 & Monterrey & Cumbres Elite \\
\hline
\end{tabular}

(Elaboración propia)

\section{Municipio de Guadalupe.}

El municipio de Guadalupe tiene un total de 678,006 habitantes, donde la media de edad por habitante es de 29 años. Cuenta con un total de viviendas habitadas de 172, 309 y un promedio de 3.9 de habitantes por vivienda, 167, 119 de las 172, 309 viviendas cuentan con energía eléctrica, de las cuales 76, 923 disponen de computadora en sus domicilios. Cuenta con 40 escuelas de bachillerato y un $99.6 \%$ de alfabetización en hombres de entre 15 y 24 años, $99.7 \%$ de alfabetización en mujeres de entre 15 y 24 años.

Tabla 5: Municipio de Guadalupe

\begin{tabular}{|c|c|}
\hline Municipio de Guadalupe & \\
\hline Características & Datos \\
\hline Total de habitantes & 678,006 \\
\hline Media de edad por habitantes & 29 años \\
\hline Viviendas habitadas & 172,309 \\
\hline Promedio de habitantes por vivienda & 3.9 \\
\hline Viviendas que cuentan con energía eléctrica & 167,119 \\
\hline Viviendas que cuentan con computadora & 76,923 \\
\hline Escuelas de bachillerato & 40 \\
\hline $\begin{array}{l}\text { Promedio de alfabetización en hombres y } \\
\text { mujeres. }\end{array}$ & $\begin{array}{l}99.6 \% \text { hombres } \\
99.7 \% \text { mujeres }\end{array}$ \\
\hline
\end{tabular}

(Elaboración propia, Fuente: INEGI) 
A continuación se desglosan por colonias los datos relevantes del contexto sociodemográfico de los estudiantes agresores, en la siguiente tabla.

Tabla 6: Contexto social de los Agresores por colonias.

\begin{tabular}{|c|c|c|c|c|c|c|c|}
\hline \multicolumn{2}{|c|}{$\begin{array}{l}\text { Colonia Valle del } \\
\text { Contry, 1er. Sector. }\end{array}$} & \multicolumn{2}{|c|}{ Jardines de linda vista } & \multicolumn{2}{|l|}{$\begin{array}{l}\text { Rincón de la } \\
\text { primavera }\end{array}$} & \multicolumn{2}{|c|}{ Bosques del Contry } \\
\hline Características & Datos & Características & Datos & Características & Datos & Características & Datos \\
\hline $\begin{array}{l}\text { Total de } \\
\text { viviendas }\end{array}$ & 121 & $\begin{array}{l}\text { Total de } \\
\text { viviendas }\end{array}$ & 34 & $\begin{array}{l}\text { Total de } \\
\text { viviendas }\end{array}$ & 82 & $\begin{array}{l}\text { Total de } \\
\text { viviendas }\end{array}$ & 57 \\
\hline $\begin{array}{l}\text { Viviendas } \\
\text { habitadas }\end{array}$ & 119 & $\begin{array}{l}\text { Viviendas } \\
\text { habitadas }\end{array}$ & 34 & $\begin{array}{l}\text { Viviendas } \\
\text { habitadas }\end{array}$ & 76 & $\begin{array}{l}\text { Viviendas } \\
\text { habitadas }\end{array}$ & 57 \\
\hline Población total & 439 & Población total & 97 & Población total & 295 & Población total & 220 \\
\hline $\begin{array}{l}\text { Edades de la } \\
\text { población: } \\
0 \text { a } 14 \text { años } \\
15 \text { a } 29 \text { años } \\
30 \text { a } 59 \text { años } \\
60 \text { o más años }\end{array}$ & $\begin{array}{l}88 \\
144 \\
155 \\
24\end{array}$ & $\begin{array}{l}\text { Edades de la } \\
\text { población: } \\
0 \text { a } 14 \text { años } \\
15 \text { a } 29 \text { años } \\
30 \text { a } 59 \text { años } \\
60 \text { o más años }\end{array}$ & $\begin{array}{l}34 \\
19 \\
39 \\
5\end{array}$ & $\begin{array}{l}\text { Edades de la } \\
\text { población: } \\
0 \text { a } 14 \text { años } \\
15 \text { a } 29 \text { años } \\
30 \text { a } 59 \text { años } \\
60 \text { o más años }\end{array}$ & $\begin{array}{l}68 \\
83 \\
136 \\
8\end{array}$ & $\begin{array}{l}\text { Edades de la } \\
\text { población: } \\
0 \text { a } 14 \text { años } \\
15 \text { a } 29 \text { años } \\
30 \text { a } 59 \text { años } \\
60 \text { o más años }\end{array}$ & $\begin{array}{l}77 \\
42 \\
95 \\
6\end{array}$ \\
\hline $\begin{array}{l}\text { Viviendas que } \\
\text { cuentan con } \\
\text { electricidad }\end{array}$ & 119 & $\begin{array}{l}\text { Viviendas que } \\
\text { cuentan con } \\
\text { electricidad }\end{array}$ & 34 & $\begin{array}{l}\text { Viviendas que } \\
\text { cuentan con } \\
\text { electricidad }\end{array}$ & 76 & $\begin{array}{l}\text { Viviendas que } \\
\text { cuentan con } \\
\text { electricidad }\end{array}$ & 57 \\
\hline $\begin{array}{l}\text { Viviendas que } \\
\text { tienen } \\
\text { televisión }\end{array}$ & 119 & $\begin{array}{l}\text { Viviendas que } \\
\text { tienen } \\
\text { televisión }\end{array}$ & 32 & $\begin{array}{l}\text { Viviendas que } \\
\text { tienen } \\
\text { televisión }\end{array}$ & 76 & $\begin{array}{l}\text { Viviendas que } \\
\text { tienen } \\
\text { televisión }\end{array}$ & 57 \\
\hline $\begin{array}{l}\text { Viviendas que } \\
\text { tienen } \\
\text { computadora }\end{array}$ & 119 & $\begin{array}{l}\text { Viviendas que } \\
\text { tienen } \\
\text { computadora }\end{array}$ & 26 & $\begin{array}{l}\text { Viviendas que } \\
\text { tienen } \\
\text { computadora }\end{array}$ & 73 & $\begin{array}{l}\text { Viviendas que } \\
\text { tienen } \\
\text { computadora }\end{array}$ & 56 \\
\hline $\begin{array}{l}\text { Viviendas que } \\
\text { cuentan con } \\
\text { servicio de } \\
\text { internet }\end{array}$ & 119 & $\begin{array}{l}\text { Viviendas que } \\
\text { cuentan con } \\
\text { servicio de } \\
\text { internet }\end{array}$ & 26 & $\begin{array}{l}\text { Viviendas que } \\
\text { cuentan con } \\
\text { servicio de } \\
\text { internet }\end{array}$ & 73 & $\begin{array}{l}\text { Viviendas que } \\
\text { cuentan con } \\
\text { servicio de } \\
\text { internet }\end{array}$ & 56 \\
\hline
\end{tabular}




\begin{tabular}{|c|c|c|c|c|c|c|c|}
\hline $\begin{array}{l}\text { Viviendas sin } \\
\text { alguna de las } \\
\text { tecnologías de } \\
\text { la información } \\
\text { y comunicación }\end{array}$ & 0 & $\begin{array}{l}\text { Viviendas sin } \\
\text { alguna de las } \\
\text { tecnologías de } \\
\text { la información } \\
\text { y } \\
\text { comunicación }\end{array}$ & 0 & $\begin{array}{l}\text { Viviendas sin } \\
\text { alguna de las } \\
\text { tecnologías de } \\
\text { la información } \\
\text { y } \\
\text { comunicación }\end{array}$ & 0 & $\begin{array}{l}\text { Viviendas sin } \\
\text { alguna de las } \\
\text { tecnologías de } \\
\text { la información } \\
\text { y } \\
\text { comunicación }\end{array}$ & 0 \\
\hline
\end{tabular}

Cumbres Elite, 4to sector

\begin{tabular}{|c|c|}
\hline Características & Datos \\
\hline Total de viviendas & 47 \\
\hline Viviendas habitadas & 44 \\
\hline Población total & 141 \\
\hline Edades de la población: & \\
\hline 0 a 14 años & 29 \\
\hline 15 a 29 años & 41 \\
\hline 30 a 59 años & 66 \\
\hline 60 o más años & 3 \\
\hline Viviendas que cuentan con electricidad & 44 \\
\hline Viviendas que tienen televisión & 43 \\
\hline Viviendas que tienen computadora & 41 \\
\hline Viviendas que cuentan con servicio de internet & 41 \\
\hline $\begin{array}{l}\text { Viviendas sin alguna de las tecnologías de la información y } \\
\text { comunicación }\end{array}$ & 0 \\
\hline
\end{tabular}

(Elaboración propia, Fuente: INEGI)

Aunque por los alcances de la presente investigación no es posible realizar una generalización, si es posible caracterizar el contexto social y demográfico de los sujetos entrevistados, en este caso de aquellos que hemos ubicado en la categoría de agresores. Aunque cada uno de estos jóvenes agresores reside en el municipio de Guadalupe, la heterogeneidad tanto demográfica como socioeconómico de este municipio hace que ubicar a los informantes en esta escala espacial no sea suficiente para dar cuenta de las características que constituyen su entorno, el cual es un elemento explicativo importante del fenómeno del ciberacoso. 
Sin embargo, como se aprecia en las tablas anteriores, los indicadores sociales y demográficos descritos en una escala con mayor desagregación, en este caso a nivel de colonia, hacen posible ubicar con mayor precisión el entorno desde el punto de vista sociodemográfico de los sujetos. De esta manera, podemos apreciar que aunque el municipio de Guadalupe presenta una heterogeneidad considerable en cuanto a los indicadores considerados, los sujetos por el contrario presentan entornos sociodemográficos muy similares, que podemos ubicar como zonas favorecidas que posibilitan el uso de redes sociales.

Este mayor desarrollo socio económico se aprecia claramente al considerar el número de viviendas que cuentan con servicios indispensables para el uso de redes sociales: mientras que en el municipio de Guadalupe únicamente el $45 \%$ del total de viviendas cuentan con computadora, en las colonias donde residen los agresores cuentan con este servicio prácticamente la totalidad de los domicilios. Esto confirma que son las características del entorno determinantes tanto para ser acosador o víctima, en este caso la posibilidad de contar tanto con energía eléctrica y computadora constituyen condiciones fundamentales para participar del fenómeno del ciberbullying. Aunque parezca una obviedad, debido a que únicamente pueden participar del fenómeno aquellos jóvenes con las posibilidades materiales para hacerlo, considerarlo explícitamente permite ubicar tanto a los agresores como a las víctimas en un contexto sociodemográfico particular; aquél con las condiciones tanto económicas como materiales (energía eléctrica, computadora, internet, tiempo libre) suficientes para permitir el uso cotidiano de redes sociales, es decir que podríamos aseverar que no es un fenómeno que se presente en contextos de marginación.

Por otro lado, llama la atención que las colonias que conforman este entorno socio demográfico corresponden a zonas geográficas con un predominio muy claro de jóvenes, lo que es indicativo de ser contextos que además de brindar las posibilidades materiales para el ciberacoso tal y como fue discutido anteriormente, genera a su vez condiciones sociales no materiales favorecedoras del uso de la violencia por medio de las redes sociales. En este caso es posible pensar que el entorno juega un papel determinante en el fenómeno del ciberacoso permitiendo también una retroalimentación ideológica entre grupos etéreos que comparten intereses y comportamientos.

En este sentido es posible afirmar que el ciberbullying no constituye un fenómeno de carácter individual sino colectivo, no únicamente por la cantidad de jóvenes que participan de éste, sino porque son las características de la colectividad social del entorno, que generan las condiciones necesarias para la persistencia del empleo de la violencia en las redes sociales. Esta consideración es fundamental para el diseño de intervenciones dirigidas a erradicar el fenómeno, puesto que con lo discutido podemos señalar la necesidad de intervenciones sociales colectivas (comunitarias o poblacionales) si se quiere lograr este objetivo. 
Lo anterior permite cuestionar si las intervenciones basadas en la mediación, que de manera general operan a un nivel interpersonal (entre la víctima y el victimario) pueden lograr ser efectivas para prevenir o erradicar el ciberbullying.

\section{Consecuencias}

Las consecuencias de la violencia cibernética impactaron principalmente en la autoestima, el desprestigio y el desequilibrio emocional de quienes jugaron el papel de víctima, cuando por el contrario, el victimario asume un rol principal en el juego de poder, se empodera.

“¿Cómo que qué sentí? Depresión estaba deprimida, baja autoestima y tendencias suicidas y venganza. (-“"Tendencias suicidas”?) Sí, sentía que era mucho que no podía sola, ahí fue cuando ya le dije a mis papás que ya no aguantaba, me quería cambiar de prepa ya no quería venir, no quería verlos (¿Fueron tus compañeros, los que te molestaban en redes sociales?) Sí, unos sí, otros no, otros no me decían cosas a la cara pero luego los veía desde otro face de una amiga que comentaban, que sí me parezco a la morsa. Claro que ya no quería salir de mi casa, que nadie me viera, ya no quería nada, ni comer ni nada, por eso mis papás me llevaron a terapia con psicólogo, y ya ahí el psicólogo nos dijo que podía mandarme con un psiquiatra que él conocía y me recetó unas pastillas que se llaman paxil, no he dejado de tomarlas todavía, las necesito" (I., 17 años).

La manera en que esta narradora señala el impacto del acto violento a través de las redes sociales podría parecer una broma inofensiva pero en realidad es determinante en la vida de un adolescente, al grado de necesitar tratamiento psicológico y psiquiátrico para sobrellevar las consecuencias de ser víctima de ciberbullying.

Por otra parte, el que juega el papel del agresor no presenta remordimientos por su comportamiento, sino que se sienten empoderados al realizar el acto violento.

"Me sentía bien, nadie sabía que era yo, nadie sabe que fui yo, se lo imaginan pero no saben, sí me preguntaron que, "eh, fuiste tú, verdad”, pero no nunca les dije si sí. Y es que sí fue a mucha gente, morras sangronas o de esas que se creen mucho, yo no esperaba que se propagara, era más como juego, primero tenía como 40 followers en twitter, todas a las que molestaba y de repente empezaron a seguirme más personas, amigos de las que molestaba, novios, amigos míos que no sabían que era yo, y así, me amenazaban, que cuando supieran que era yo me iban a hacer no sé qué, y así, llegué a los 999 followers como en tres meses y entre más les jodía más me seguían, entre más personas seguían más poder de joder tenía, si una cuenta equis pocos followers te molesta no importa, nadie lo lee, 
pero cuando ya es una cuenta con muchos seguidores las cosas cambian, te respetan más." (C., 17 años).

Es muy clara la posición de empoderamiento del sujeto entrevistado, a partir de diversos factores, por una parte la presencia del anonimato permite que se consuman actos violentos por no temer a las consecuencias, por otra parte, la relación de poder frente a sus víctimas es mayor debido a la cantidad de personas a las que puede llegar la agresión cibernética a través de todos los usuarios conectados en la red.

\section{Estrategias de intervención}

En cuanto a las posibles estrategias de intervención, los estudiantes entrevistados, tanto víctimas como victimarios, aseguraron que de existir un mecanismo de intervención, no se podría llegar siempre a resolver el conflicto.

“De arreglar frente a frente con ellos? No, no se puede arreglar algo así, lo que me hicieron fue afectarme delante de todos, a menos que fuera delante de todos, una disculpa que diga que no soy nada de lo que dicen que soy, eso sí, pero yo nunca voy a perdonar eso, nunca, fue feo, fue malo. Nunca se lo voy a perdonar." (K., 17 años).

"Sí, sí sé qué es la mediación, nos mandaron llamar a psicopedagogía pero yo no fui, no sé los otros. No, para qué, ya los veo en el salón, no entienden, si ni tu familia entiende lo que esto te afecta, ellos tampoco entienden, no se puede resolver, ni con disculpas ni aunque digan que ya no lo van a hacer, como quiera soy el mongol." (A., 16 años).

"Creo que habría que castigar a aquellos que hacen públicos datos privados o fotos de las personas sin su consentimiento. Creo que interactuar con otros usuarios no debería ser considerado bullying o un delito.Tan sencillo que es bloquear o silenciar a aquellos que te molestan. Molestarse es caer en su juego y dejarlos ganar. No me interesa verlos ni que me vean (a las victimas)." (P., 17 años).

Así mismo manifestaron la nula voluntad para someterse a algún proceso de resolución de conflicto lo que descarta la posibilidad de someterse a una mediación escolar.

\section{DISCUSIÓN}

El presente estudio permitió conocer las experiencias sobre el ciberbullying de los estudiantes del nivel medio superior del municipio de Monterrey, además de examinar cómo se desarrolla el fenómeno y los elementos que intervienen en el mismo. En este sentido es importante destacar que los casos aquí estudiados no pretenden hacer generalizaciones acerca del ciberbullying, sin embargo, a través del análisis del contexto 
experimentado por estos estudiantes se profundizó sobre el conocimiento existente del fenómeno ofreciendo elementos de evidencia empírica para futuras investigaciones y permitiendo la construcción de hipótesis que deberán ser contrastadas en investigaciones posteriores. A continuación, se presentan las conclusiones de este estudio.

\section{Elementos determinantes para convertirse en víctima o agresor.}

Las experiencias de ciberbullying en estudiantes del nivel medio superior de preparatorias pertenecientes a la UANL en el municipio de Monterrey, se encuentran mediadas a partir de la interacción entre los factores personales, interpersonales y las motivaciones externas de los sujetos, constituyendo estos elementos los determinantes fundamentales del fenómeno del ciberbullyng.

Entre los factores personales no se documentaron elementos que pudiesen hacer pensar la existencia de diferencias significativas en torno al sexo, pudiendo señalar con esto, que al menos en los sujetos participantes el sexo y por lo tanto la construcción social que se hace a partir de este mismo, no es determinante para la constitución de un individuo como agresor o víctima de ciberbullying. Por otro lado, si fue posible encontrar otras características individuales propias de agresores y víctimas: entre las características del agresor se encontraron alta autoestima y buen rendimiento escolar, frente a los promedios más bajos de las víctimas.

Respecto a los factores interpersonales, es posible afirmar la existencia de una relación de determinación entre el intento de ajuste social de un individuo y asumir el rol de agresor. Esta relación puede ser explicada al considerar que convertirse en generador de violencia indirecto en el contexto cibernético es usual y es visto como una forma de integración de una sociedad cibernética. De esta manera, la agresión cibernética es vista entre los jóvenes como una forma de asumir conductas que pueden ser aceptadas entre sus pares y que se expresan en comportamientos que incentivan la interacción violenta entre la víctima y su agresor como cuando se retroalimentan positivamente los descalificativos, insultos y otras formas de violencia a través de las redes sociales. Así mismo, se determinó que el contexto socio demográfico brinda las herramientas tanto materiales como ideológicas necesarias para generar el fenómeno. De esta manera, la disponibilidad de computadora y acceso a internet, en un medio social que favorece las interacciones de acoso conforma un contexto propenso para el ciberbullyng.

\section{Consecuencias y motivaciones.}

Los principales sentimientos manifestados en las víctimas se asocian a baja autoestima, humillación, depresión, desequilibrio emocional y tristeza por ser afectados directamente en su persona frente a todos los demás miembros de su red social. Por su parte, las principales motivaciones que llevan a los agresores a cometer el ciberbullying son la envidia, la venganza, los celos, el aburrimiento y la diversión. 


\section{Desarrollo del fenómeno.}

Las redes sociales cibernéticas son el lugar donde ocurren todas las ciberagresiones ya que proporcionan los medios idóneos para detonar el acto. El proceso de violencia cibernética empieza a partir de las motivaciones internas del agresor que en ocasiones es un agresor victimizado. Para que el ciberbullying tenga un impacto considerable en la víctima tiene que tener carácter colectivo, entendiéndose para esto que el universo cibernético de la víctima ha sido afectado frente a todos los individuos de su red social. Es decir, el ciberbullying afecta la realidad de la víctima tanto cibernética al ser a través de las redes sociales, como físicamente al ser frente a personas que son parte de su realidad cotidiana, en este caso sus pares escolares.

\section{Intervención.}

La mediación por su carácter interpersonal solo podría contribuir a la solución del conflicto entre víctima y el agresor, sin embargo, no en el ciberbullying por su característica colectiva en la que para el efecto bola de nieve necesita de la interacción de terceros involucrados como los agresores indirectos y que como se discutió constituyen actores fundamentales para la generación del fenómeno. En este caso se requieren de intervenciones de otro tipo como las educativas.

\section{CONSIDERACIONES FINALES}

Nos parece conveniente continuar impulsando investigaciones que analicen el ciberbullying a gran escala para determinar cómo impacta este fenómeno a nivel estatal, en los diferentes niveles educativos para determinar de qué manera se pueden desarrollar y promover medidas de culturización para prevenir el acoso cibernético. Asimismo, es conveniente señalar que los hallazgos que aporta la presente investigación que han sido obtenidas principalmente a partir de un abordaje cualitativo puedan ser corroborados a través de una muestra estadísticamente representativa que permita generalizar estos resultados para toda la población escolar en la entidad. 


\section{LISTA DE REFERENCIAS}

Aviles, J., García-López, M., \& Caballo, V. (2011). el maltrato entre iguales: bullying. Behavioral psychology, 57-90.

Beran, T., \& Li, Q. (2008). the relationship between cyberbullying and school bullying. The journal student wellbeing, 16-33.

Berkowitz, L. (1996). Agresión, causas, consecuencias y control (1era edición ed.). País Vasco: Desclée de Brouwer.

Calmaestra, J. (2011). Cyberbullying: prevalencia y características de un nuevo tipo de bullying indirecto. Córdoba: Universidad de Córdoba.

Cobo, P., \& Tello, R. (2008). Bullying en México. México: Editorial Lectorum.

Creswell, J. (2003). Research desing: Quialitative, quantitative, and mixed methods approaches. CA: Thousand Oaks.

Creswell, J. (2005). educational research: planning, conducting, and evaluating quantitative and cualitative research. Upper saddle river: Pearson Education.

Denzin, N., \& Lincoln, Y. (2000). Handbook of quialitative research. Thousand Oaks: Sage.

Escalera, A., Silva, L., Cointreras, A. (2019) Derecho a una escuela libre de violencia. Realidades, Universidad autónoma de Nuevo León. Págs. 95-120

Estevez, E. (2005). violencia, victimización y rechazo escolar en la adolescencia. Valencia: Publicaciones Universidad de Valencia.

Garaigordobil, M. (2013). Cyberbullying.Screening de acoso entre iguales. Madrid: TEA.

Garaigordobil, M., \& Martínez-Valderrey, V. (2014). Cyberprogram 2.0: Efectos en la mejora de la conducta social durante la adolescencia. Internacional Journal of developmental and Educational Psychology, 577-587.

Goode, W. (2008). Metodos de investigación social. México: Trillas.

Harries, S. y. (2003). El acoso en la escuela. Los agresores, las víctimas y los espectadores. México: Paidós. 
Hernandez, R., Fernandez-Collado, C., \& Baptista, P. (2006). Metodología de la investigación. México: Mc Graw-Hill.

Hinduja, S., \& Patchin, J. (2013). 2013. Social influences on cyberbullying behavior among middel and high school sudents., Journal youth adolescence.

Konig, C., Maekawa, H., \& Schiebel, E. (2010). Mutual regulation of cyclin-dependent kinase and the mitotic exit network. Journal Cell Biol, 51-68.

Martínez, M. (2004). Ciencia y arte en la metodología cualitativa. México: Trillas.

Olewus, D. (2005). Bullying en la escuela: datos e intervención. En J. Sanmartín, Violencia y Escuela (págs. 13-30). Valencia: Centro Reina Sofía para el estudio de la violencia.

Olewus, D. (2012). Cyberbullying: an overrated phenomenon? European journal of developmental psychology, 520-538.

Pollio, H. (1997). The phenomenology of everyday life. Cambridge: Cambridge University Press.

Redorta, J. (2004). Cómo analizar conflcitos. Barcelona: Paidós.

Scheneider, S., O’Donell, L., Stueve, A., \& Coulter, R. (2012). Cyberbullying, scholl bullying and psychological distress: a regional census of high school students. American Journal of public health, 171-177.

Seltiz, C. J. (1998). Metodos de relacion de investigaciones sociales. Madrid.: Rialp.

Trautmann, M. (2008). Maltrato entre pares o bullying. Una vision actual. Revista chilena de pediatría, 13-20.

Von-Eckartsberg, R. (1998). Introducin existencial-phenomenological pychology. En R. Valle, Phenomenological Inquiry in psychology: Existencial and transpersonal dimensions (págs. 3-20). New York: Plenum Press. 